\title{
6
}

\section{Evolution of production networks in the Asia-Pacific region: A vision in value-added and employment dimensions}

\section{Hubert Escaith, Satoshi Inomata and Sébastien Miroudot}

\section{Introduction}

As production activities are increasingly being fragmented and relocated across borders, a number of people have started to use the expression 'global value chain' (GVC), yet often without knowing what it really encompasses. The concept of GVCs was first elaborated through the discussions of the Global Value Chains Initiative (2000-05) sponsored by the Rockefeller Foundation, and further crystallised in the seminal paper of Gereffi, Humphrey and Sturgeon (2005). Since then, substantial effort has been invested in empirical studies that attempt to capture the nature of global production sharing. Thanks to the successful development of the trade in value-added (TiVA) database by the Organisation for 
Economic Co-operation and Development (OECD) and the World Trade Organization (WTO), ${ }^{1}$ 'mapping GVCs' has now become one of the key research agendas in the relevant academic fields. ${ }^{2}$

Given this context, we aim to present empirical evidence on the key features of GVCs in the Asia-Pacific region using a multi-country inputoutput model as a principal drawing tool. The structure of the chapter is as follows. The first section provides a brief overview of empirical challenges for GVC studies and shows how the method of input-output analyses can complement the traditional approach. The second section presents a general picture of global production networks, with a particular focus on the evolution of vertical production system among countries. The third section demonstrates the development of value-added flows across countries in relation to major trade agreement schemes. The fourth section considers the effect of firms' global activities on domestic employment, which has been a central subject of political debates over time. The final section concludes the chapter.

\section{An overview of empirical challenges for mapping GVCs}

The early challenges involved in developing quantitative descriptions of GVCs are exemplified by the studies that utilise firm-specific business records. They generally aim to identify the structure of production processes and/or the sales networks of some particular products, based on the data provided by the manufacturers themselves or the 'teardown reports' of private consulting companies (Sturgeon, Nielsen, Linden, Gereffi \& Brown, 2013).

Pioneering research in this area includes the work of Dedrick, Kraemer and Linden (2008) who conducted an analysis of the value-added structure of four representative products-Apple's iPod and video iPod, and Hewlett Packard's and Lenovo's laptop computers - using the information from business reports. Among other findings, the study revealed that a video

\footnotetext{
1 Hereafter, the OECD-WTO TiVA database.

2 However, note that the main objective of Gereffi et al. (2005) is to examine the governance structures of organising cross-border production networks by focusing on a particular relationship between a lead firm and a service supplier. Hence, the scope of the empirical analyses introduced in the present chapter is somewhat different from their original motivation. See Inomata (2017) for a survey of various analytical frameworks for GVC studies.
} 
iPod with a retail price of US $\$ 299$ in 2005 was associated with a breakdown of US $\$ 144$ for the product's factory cost, US $\$ 75$ for distribution margins and US $\$ 80$ for the profit of the lead firm (Apple); of the overall factory cost, only US $\$ 3.86$ was attributable to assembly services in the People's Republic of China (PRC).

These product-level approaches are useful in illustrating the structure of production chains because they directly utilise the data provided by individual firms rather than resorting to any forms of statistical inference. However, there are a number of weaknesses associated with this approach.

First, the approach has limited applicability to the consideration of macro-economic issues, such as trade policies, because the analytical focus is only on a particular product and/or the activity of a few firms. Moreover, it is unable to capture aggregate flows of value added in the broader national context. Second, as pointed out by Dedrick et al. (2008), the majority of firm data does not explicitly identify the compensation of employees, an important component of value-added items in the national accounting framework, but merges it with other types of production costs. Third, as values are generated at every point of the production process, the value-added analysis should be able to trace all the production stages along the entire supply chain. However, the productlevel approach only considers the value-added structure of direct input suppliers (the first-tier suppliers), but leaves the rest of the value-added stream untracked. For example, a hard disk drive in an iPhone contains various sub-parts produced in different countries; therefore, it requires further decomposition of the value-added sources.

Given the limitations of this first approach, increasing attention is being directed to the use of statistical tables called multi-country input-output tables (MCIOTs). An MCIOT provides a comprehensive map of the international transactions of goods and services. This massive dataset combines national input-output tables of various countries at a given point in time. As the tables contain information on supply-use relations between industries and across countries, which are totally absent from foreign trade statistics, it is possible to identify the vertical structure of international production sharing. Further, in contrast to the product-level approach, input-output analysis covers the entire set of industries that comprise an economic system, which enables researchers to capture cross- 
border value flows at the level of a country or region. Theoretically, it has the capacity to track the value-added generation process of every product in every country at every production stage.

GVC studies using input-output tables have become increasingly prominent in the last decade, yet their origin can be traced back to the beginning of the century, when Hummels, Ishii and Yi (2001) introduced the concept of vertical specialisation (VS). The VS metric is defined as the amount of imported intermediate inputs used for the production of an exported good or, put differently, the import content of exports, which is presented as a measurement of international production sharing.

The idea was brought into the value-added context by Chen, Cheng, Fung and Lau (2009) who were the first to investigate the statistical distortions that arise from ignoring the presence of processing trade and measuring international trade in gross terms. Here, the long-debated issue of USPRC trade imbalances was fully considered in a value-added perspective. The approach is further developed and methodologically formalised in Koopman, Wang and Wei (2012), in which the PRC's national inputoutput matrices are separated into two components, one for the export processing sectors and one for the rest of the economy.

Whereas these empirical exercises relied on individual country national input-output tables, Daudin, Monperrus-Veroni, Rifflart and Schweisguth (2006) utilised the database of the Global Trade Analysis Project (GTAP) and constructed an MCIOT of 70 countries and their composite regions for the calculation of the domestic value-added content of exports, alongside indices of VS and regionalisation. Johnson and Noguera (2012) calculated the ratio of value-added exports to gross exports (referred to as the VAX ratio) as a metric of international production sharing, again using the GTAP database. This study extensively discussed the effect of production sharing on the scale of bilateral trade balances with respect to a myriad of countries and regions. In relation to the US trade deficit with the PRC, it determined that the deficit fell by 30-40 per cent when calculated in terms of value added compared with the traditional calculation. 


\section{Geometry of GVCs}

\section{A network approach to mapping value chains}

Graphs are the most intuitive approach for mapping trade networks. Despite their apparent simplicity, graphs can be subjected to more advanced analysis that enables measurement of the pivotal role that trade partners play (Escaith, 2014). A trade network is best described as directed graphs, or digraphs, because it is made of directed edges (imports from, exports to) connecting vertices (trade partners).

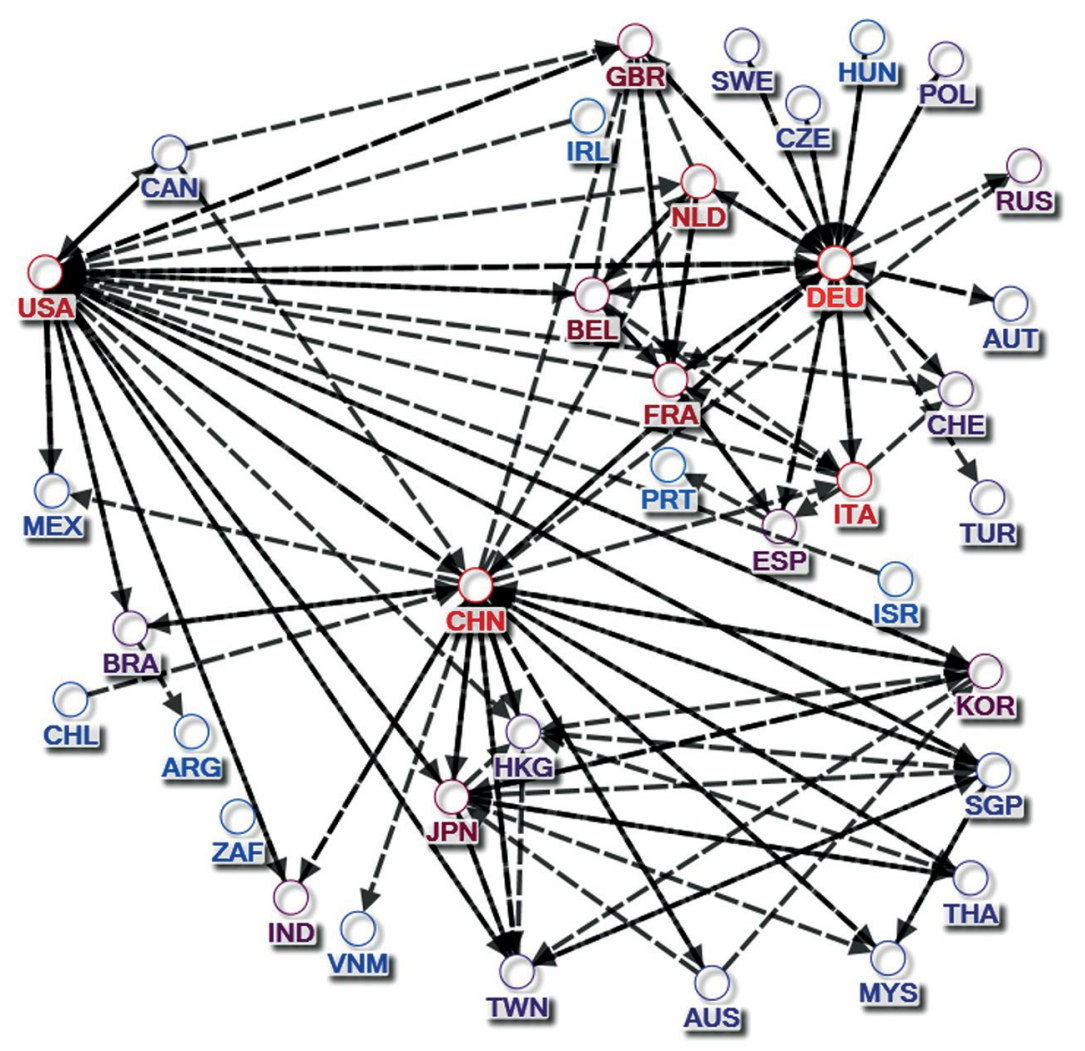

Figure 6.1: Network of trade in intermediate inputs, 2011

Note: Graph based on the 62 OECD-WTO TiVA economies and the value of their bilateral gross trade flows. The figure shows only the most important flows (over US $\$ 100$ million). The colour-coding indicates the node's centrality, ascending from blue to red.

Source: Based on UN COMTRADE data, excluding oil. 
Trade in intermediate goods and services are of particular importance for mapping international supply chains. Those flows of intermediate products represent 'business to business' interactions that closely track the extent of inter-industrial relationships between countries and sectors. Figure 6.1 shows international trade in intermediate products for the economies included in the OECD-WTO TiVA database. To simplify the graph, only the most relevant trade flows are shown; that is, only those trade flows greater than US $\$ 100$ million are shown with a solid arrow.

There are several interesting features of this graph. First, global supply chains are organised in sub-regions, each one of which is organised around one or several hubs. The European value chains have Germany as the main hub, with the UK and France as sub-centres. (The roles of Belgium and the Netherlands are also important, but more for their strategic seashipping logistic situation than for their industrial leadership.) The AsiaPacific region (the south-west part of the graph) has two poles: the PRC and the US, with Japan and South Korea as secondary hubs. (Hong Kong and Singapore play the roles of logistic platforms.)

The US plays a key role in the GVC network, as it is the main linkage between the European, Asian and North and South American countries. In the language of network analysis, the US ranks high in terms of its 'centrality'. The centrality indicator used in Figure 6.1 (page rank) is a measure of influence. The intuition behind its calculation is that if a trade partner (a node or a vertex in network analysis) influences just one other node, who subsequently influences many other nodes (who themselves influence still more others), then the first node in that chain is highly influential' (Borgatti, 2005, p. 61). In our graph, the colourcoding indicates the node's centrality, ascending from blue to red.

Therefore, a player's centrality is not only a function of its own importance in the world economy, but is also a function of the centrality of the trade partners with which it is associated. In Europe, the most influential country is Germany, followed by Italy. This may not seem intuitive, but Italy plays an important role connecting the northern part of the EU with southern economies. In the Asia-Pacific region, the two most central economies are the PRC and the US. 


\section{Evolutionary perspective of production networks in the Asia-US region}

\section{5}

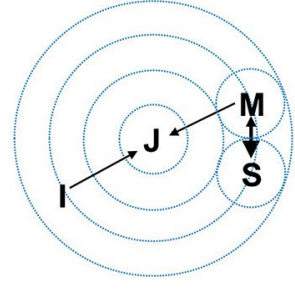

\section{5}

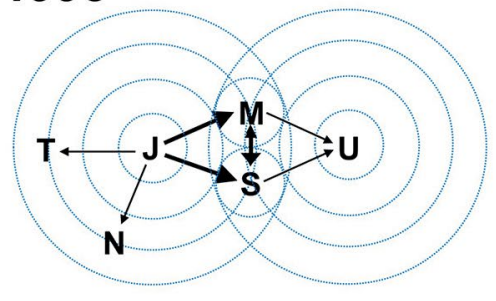

\section{5}

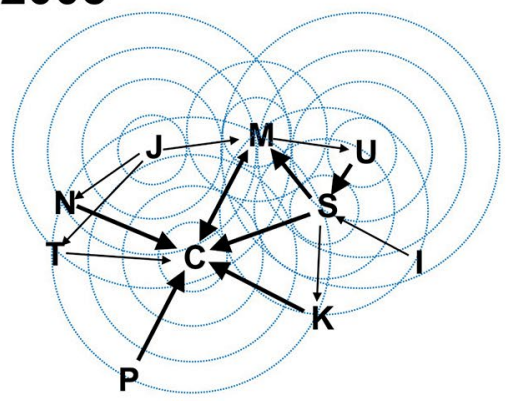

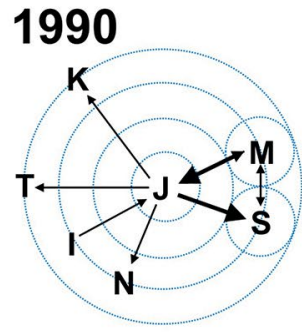

\section{0}

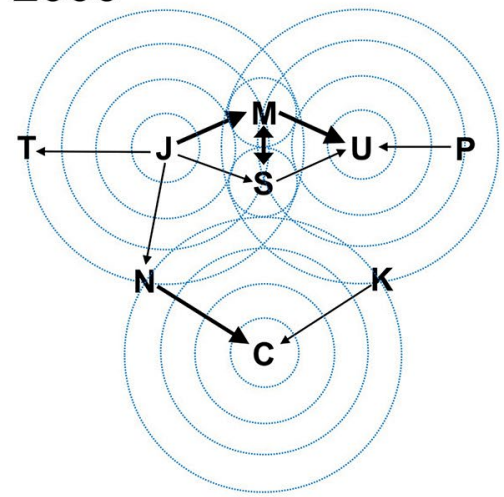

Figure 6.2: Evolution of regional supply chains in East Asia, 1985-2005 Source: Escaith and Inomata (2013).

Figure 6.2 traces the evolution of production networks in the Asia-US region from 1985 to $2005 .^{3}$ The visualisation of the calculation results is based on the method presented in Dietzenbacher, Romero and Bosma (2005),

3 Note that, in contrast to the other sections of this chapter, the analysis here does not cover the Latin American countries. 
with some graphical elaboration as developed by Inomata (2008). Arrows represent the selected supply chains among the countries of the region, with the direction of arrows corresponding to flows of intermediate products. Each arrow has two features: thickness and length. The thickness indicates the strength of linkages between industries, whereas the length, as measured against the ripple in the background, is given by the average propagation length (APL), developed in Dietzenbacher et al. (2005). ${ }^{4}$ The number of circles that an arrow crosses represents the rounded value of the APL, the average number of production stages and the level of technological fragmentation and sophistication of that particular supply chain.

The study uses the Asian International Input-Output Tables for 1985, 1990, 1995, 2000 and 2005 covering 10 economies: PRC (C), Indonesia (I), Japan (J), Korea (K), Malaysia (M), Philippines (P), Singapore (S), Thailand (T), Taipei, China (N) and the US (U).

In 1985, there were only four key players in the region: Indonesia (I), Japan (J), Malaysia (M) and Singapore (S). The basic structure of the production network was that Japan built up supply chains from resourcerich countries, such as Indonesia and Malaysia. In this initial phase of regional development, Japan drew on a substantial amount of natural resources from neighbouring countries to feed its domestic industries.

By 1990, the number of key players had increased. In addition to the four countries already mentioned, Japan had extended its supply chains for intermediate products to Korea (K), Taipei, China (N) and Thailand (T). While continuing to rely on the productive resources of Indonesia and Malaysia, Japan began to supply products to other East Asian economies, particularly to the group known as the newly industrialised economies (NIEs) of Hong Kong, Korea, Singapore and Taiwan. During this phase, the relocation of Japanese production bases to neighbouring countries was accelerating, triggered by the Plaza Accord in 1985. The development of strong linkages was observed between core parts suppliers in Japan and assembly platforms in foreign countries.

In 1995, the US (U) came into the picture. It drew on two key supply chains originating in Japan, one via Malaysia and the other via Singapore. These two countries came to bridge the supply chains between East Asia and the US. The length of the arrows between Malaysia and Singapore

4 See Technical Note 6.1 in Appendix A. 
should be noted. Compared with the other arrows, their shortness indicates that the supply chains involve fewer production stages, suggesting that the degree of processing is relatively low. Thus, the product flows between these countries are distributional rather than value adding.

In the year 2000, on the eve of its accession to the WTO, the PRC began to emerge as the third regional giant. The country entered the arena with strong production linkages to Korea and Taipei (China), and gained access to Japanese supply chains through the latter. The US also brought a new supply chain from the Philippines (P). This completed the basic structure of the tri-polar production network in the Asia-US region.

Thereafter, the regional production networks showed dramatic development. By 2005, the centre of the network had completely shifted to the PRC, pushing the US and Japan to the periphery. The PRC became the core market for products of the region from which final consumption goods were produced for export to the US and European markets. The nature of the supply chains that the PRC developed with other countries are also noteworthy. The length of the arrows surrounding the PRC indicates that the supply chains extending towards the PRC were characterised by a high degree of fragmentation and sophistication, incorporating substantial amounts of value added from each country involved in the production networks. Therefore, the competitiveness of Chinese exports was attributable not only to its cheap labour force, but also to the sophisticated intermediate products that the country received from other East Asian economies, as embedded in goods labelled 'Made in China'.

The APL method can also be used to identify the relative position of countries within the global production system. Updating the methodology proposed by Inomata (2008), Figure 6.3 presents the changes of countries' positions in the Asia-US region between 1985 and 2005 with respect to forward and backward APLs.

Reading the diagram along the top-right/bottom-left diagonal, the entire length of the supply chains that each country participates in is represented. Most economies have moved towards the top-right corner, meaning that they increased the length of their supply chains between 1985 and 2005. In particular, the PRC demonstrated an outstanding increase in the length of its supply chains. The interlinking of its domestic supply chains with 
overseas production networks was accelerated by the country's accession to the WTO in 2001, as suggested by the big leap in the value from 1985 to 2005 .

In contrast, the top-left/bottom-right direction shows the relative position of each economy within regional supply chains, as determined by the ratio of forward and backward APLs. The US and Japan, the most advanced economies in the region, are located in the upstream position, although they reduced their 'upstreamness' during the period and the US, in particular, has swapped its position with Korea. The PRC has remained in the downstream segment of regional supply chains, which reflects the country's dominant position as a final assembler of regional products.

\section{Forward APL}

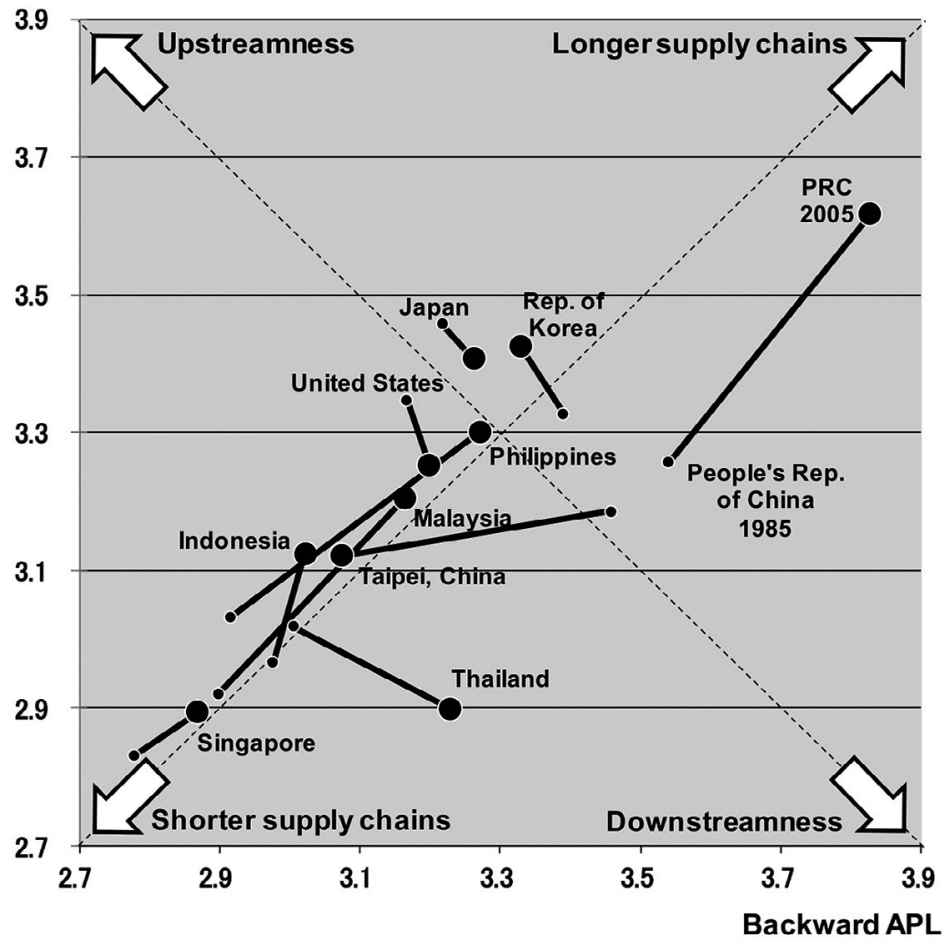

Figure 6.3: Changes in the relative positions of countries in the regional supply chains, 1985-2005

Source: Escaith and Inomata (2013). 
The other economies remain more or less in the middle range, although with two notable changes: Taipei (China) moved up into the middle cluster and Thailand moved downstream to a large extent. These changes clearly reflect the development of the roles of the two economies in the region. Taipei (China) significantly increased its electronics manufacturing services and became a major parts supplier to big computer multinationals, whereas Thailand invited and accommodated a massive inflow of Japanese car assembly plants, leading to it being named the 'Asian Detroit'.

Figure 6.4 maps the previous diagram into a one-dimensional schematisation of the relative position of countries within regional supply chains. From 1985 to 2005 , the upstream economies have been more or less clustered together, whereas the PRC and Thailand became downstream standalones. Bipolarisation between parts suppliers and final assemblers can be observed during this period.

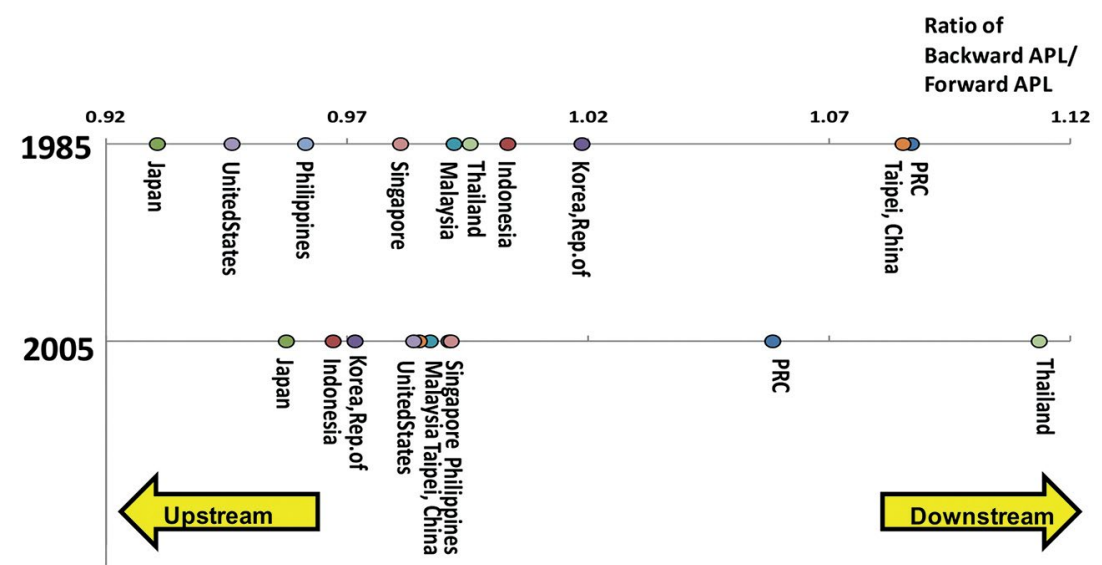

Figure 6.4: One-dimensional schematisation of the countries' relative positions, $1985-2005$

Source: Authors' drawing. 


\section{Cross-national transfer of value added}

The organisation of international production networks is, so far, mostly regional, with production taking place in a given region and the goods sold to consumers in the same region. This is especially the case in Europe, with Western Europe absorbing the manufacturing produced in Eastern Europe. It is somewhat the case in North America, but to a lesser extent, as the main source of final demand is the US.

Asia presents a slightly different picture. The supply part of the networks are regionally concentrated, yet on the demand side the networks are fairly global (across the Pacific Ocean and the Eurasian continent). This configuration originates from the early days of Japan's export-led growth strategy in the second half of the twentieth century, followed by that of the NIEs in the 1970s. The evolution took a dramatic turn with the PRC's accession to the WTO in 2001, resulting in the insertion of 700 million Chinese workers into the global economy. This was made possible through an increase in offshoring capabilities, which, in turn, was made possible by the rapid development of communication technology and transportation systems. Both of these had a tremendous effect on the PRC's comparative advantage in the region (and beyond).

Figure 6.5 presents cross-national transfers of value added in 1995 and 2011 in relation to the country coverage of major regional trade agreements (RTAs), using the OECD-WTO TiVA database (see Technical Note 6.2 in Appendix A). ${ }^{5}$ Flow values are rounded into five increments according to thresholds indicated in the figures; the size of a black spot in each cell represents the magnitude of value-added flows for a particular pair of countries, where rows are countries of origin and columns are countries of destination. ${ }^{6}$

\footnotetext{
5 For a general description of the data, see www.oecd.org/sti/ind/tiva/tivasourcesandmethods.htm 6 Owing to the layout requirements of the tables, India and Cambodia are circumscribed within the Asia-Pacific Economic Cooperation (APEC) frame, but it should be noted that these economies were not APEC members at the time of writing this article in 2016. Also, the following economies are not included in the relevant RTA frames because the database does not cover their national data: Laos, Myanmar for ASEAN and Regional Comprehensive Economic Partnership (RCEP); Peru for Trans-Pacific Partnership (TPP); and Peru and Papua New Guinea for APEC.
} 
From 1995 to 2011, we observe the following three developments:

1. Overall, value-added flows became busier.

2. Three regional clusters of value-added flows in North America, Europe and Asia can be identified throughout the period.

3. However, the regional value-added intensities became less prominent in 2011 as the US and PRC continued to extend their value chains beyond their respective regions, both in terms of origin and destination of value added.

Zooming into the constituent countries of the regional clusters, in 1995, the US value chains with Canada and Mexico were particularly impressive, following the establishment of the North American Free Trade Agreement in 1994. In Europe, Germany and France are the regional centres of value flows. By 2011, US value chains penetrated all over the world, whereas the European countries, other than Germany and France, also increased their contribution to regional value flows. In Asia, in contrast, valueadded trade is mostly concentrated within the trio of the PRC, Japan and the Republic of Korea. Other economies, including the Association of Southeast Asian Nations (ASEAN) economies, did not register their presence in regional value networks. In view of regional agreements, the influence of the US over Asian countries is quite evident in any form of RTA frameworks.

7 A parallel argument from a different perspective is given in Miroudot and Nordstrom (2015). 
ASIAN ECONOMIC INTEGRATION IN AN ERA OF GLOBAL UNCERTAINTY

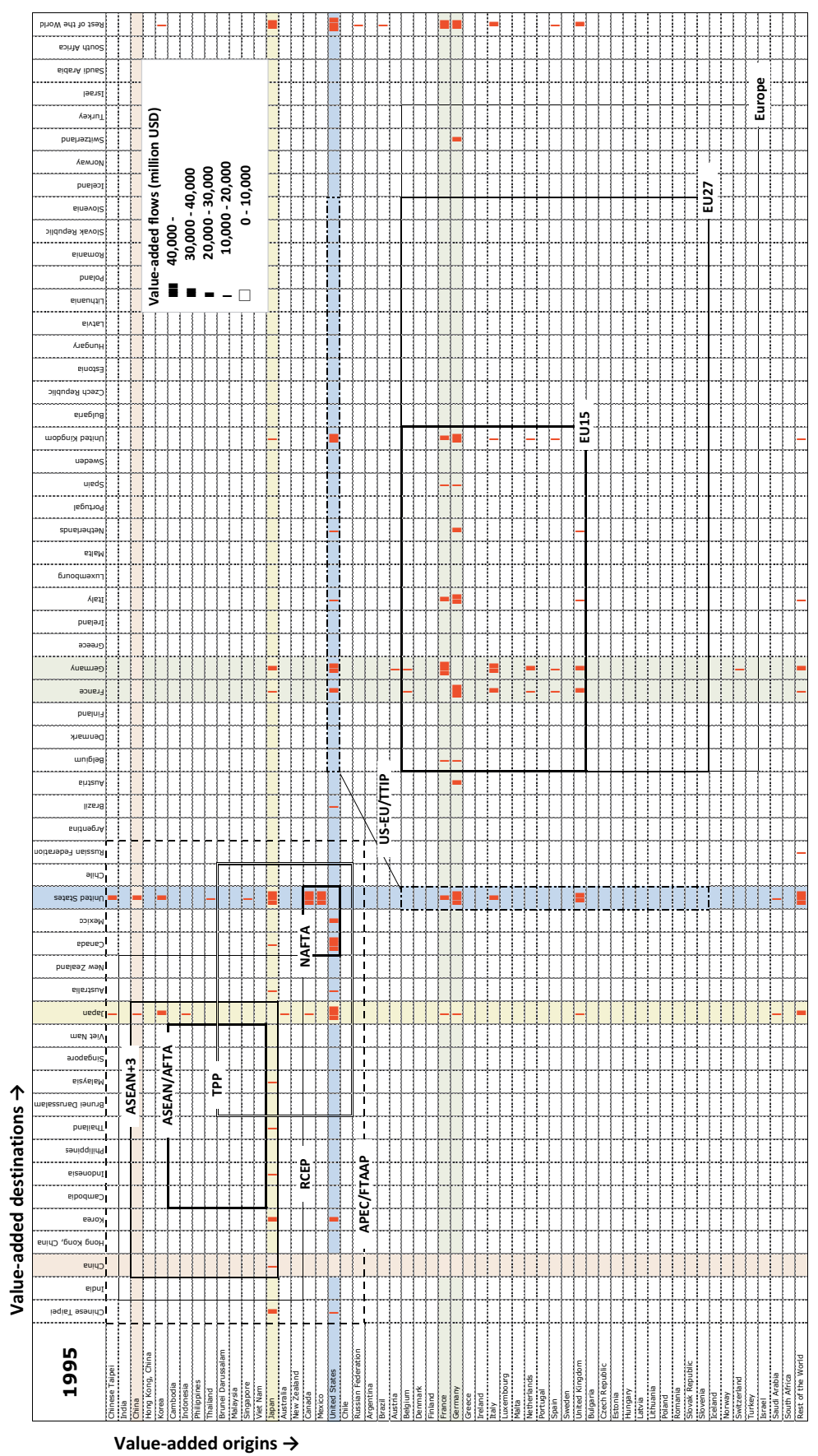

Figure 6.5a: TiVA from a regional perspective, 1995

Source: Authors' design, based on the OECD-WTO TiVA database. 
6. EVOLUTION OF PRODUCTION NETWORKS IN THE ASIA-PACIFIC REGION

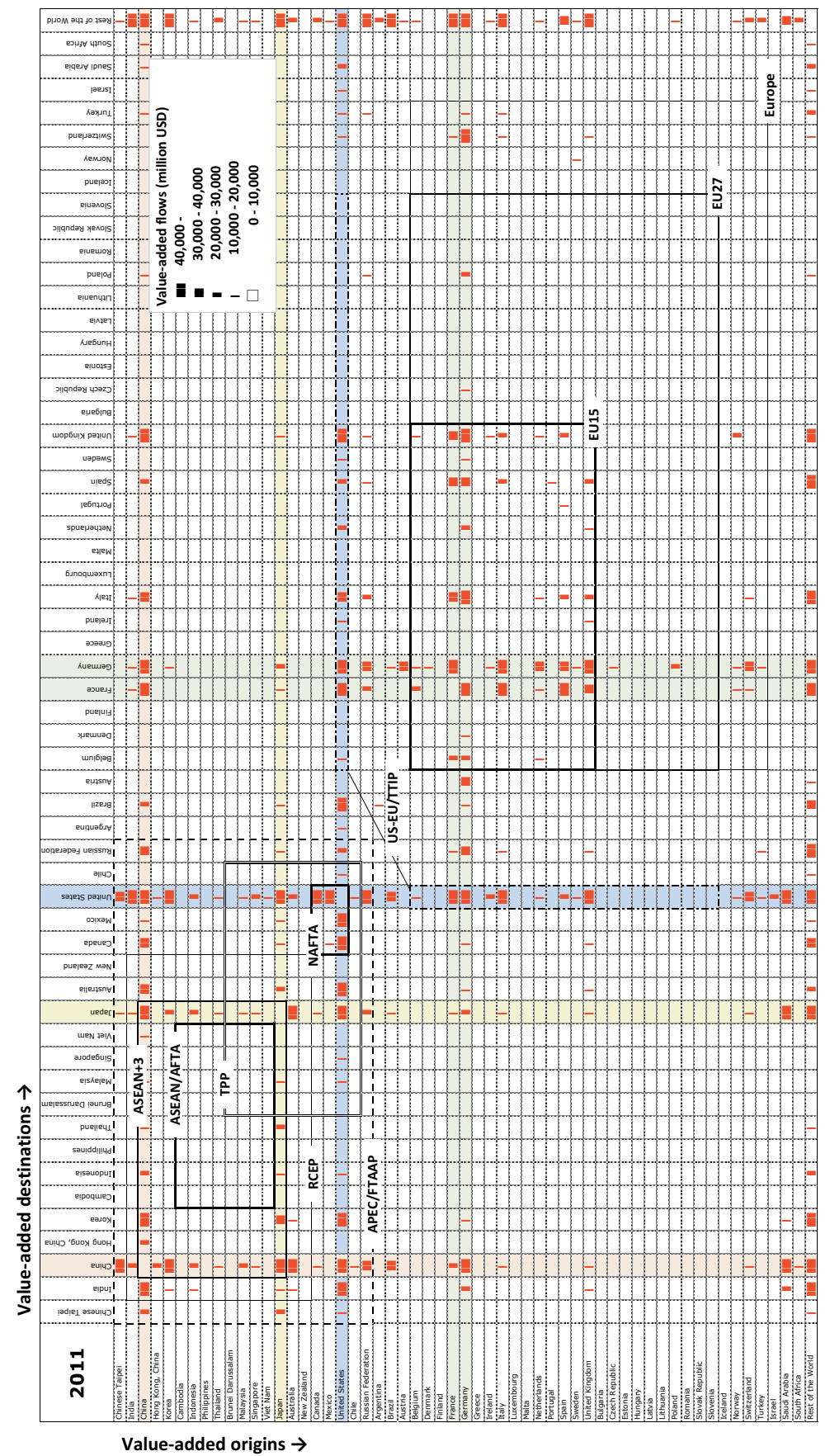

Figure 6.5b: TiVA from regional perspective, 2011

Source: Authors' design, based on the OECD-WTO TiVA database. 
Table 6.1 summarises the amount of value added captured by each RTA framework. Based on the recognition that the expansion of membership assumes non-trivial costs to the scheme, ${ }^{8}$ the column of the country averages indicates the 'efficiency' of respective RTAs in terms of capturing value added. The table shows that the most efficient RTA is, potentially, the Trans-Pacific Partnership (TPP), followed by the Free Trade Area of the Asia-Pacific (FTAAP).

Table 6.1: Numeric summary of TiVA from the Asia-Pacific regional perspective, 1995-2008

\begin{tabular}{|l|r|r|r|}
\hline $\begin{array}{l}\text { Regional trade agreement/ } \\
\text { Free trade area }\end{array}$ & $\begin{array}{l}\text { No. of member } \\
\text { economies }\end{array}$ & $\begin{array}{l}\text { Intra-regional trade } \\
\text { in value added }\end{array}$ & $\begin{array}{c}\text { Million USD } \\
\text { Average per } \\
\text { economy }\end{array}$ \\
\hline ASEAN/AFTA & 8 & $1,399,015$ & 174,877 \\
\hline ASEAN+3 & 11 & $14,173,082$ & $1,288,462$ \\
\hline ASEAN+6/RCEP & 14 & $17,408,587$ & $1,243,471$ \\
\hline TPP & 11 & $22,924,391$ & $2,084,036$ \\
\hline APEC/FTAAP & 18 & $34,249,601$ & $1,902,756$ \\
\hline
\end{tabular}

Note: ASEAN = Association of Southeast Asian Nations; AFTA = ASEAN Free Trade Area; APEC = Asia-Pacific Economic Cooperation forum; RCEP = Regional Comprehensive Economic Partnership.

Source: Authors' calculation, based on the OECD-WTO TiVA database.

\section{Effect of GVCs on employment}

In view of the high rate of unemployment affecting many open economies, the net effect of GVCs on employment was the subject of heated debate in the years following the global crisis of 2008-09. A recent review from the World Bank (Farolle, 2016) pointed out that the issues are mainly concentrated in developed countries, where lower-skilled workers are exposed to higher chances of job loss, whereas countries with large labour surpluses and low wages have observed relatively strong job growth following their GVC integration.

8 In addition to the bureaucratic costs of plurilateral negotiation, an accompanying risk is having to give up the embodiment of some 'deeper' rules in exchange for term settlement among the larger number of parties, with different levels of institutional development. 
Promoting labour standards in GVCs is often considered a win-win situation for all concerned, as workers in developing countries benefit from improved working conditions and exporting firms experience productivity gains that assist them to remain competitive. However, this positive viewpoint is not unanimously accepted. Economic success may not always be accompanied by higher wages and social upgrading, and some authors have pointed to the existence of regressive upgrading patterns, especially in textile and apparel industries. ${ }^{9}$

In the present chapter, we adopt a sectoral approach and link the OECDWTO TiVA database with sectoral employment statistics by skill levels. The method developed for measuring the generation and cross-border transfers of value added also enables researchers to map the job content of imports and exports (see Technical Note 6.3 in Appendix A). ${ }^{10}$ Figure 6.6 indicates that an increasing number of jobs are related to export activities over the period from 1995 to 2011. Here, we count jobs in exporting industries plus employment generated indirectly through domestic supply chains (the nexus of suppliers of intermediate goods and services). The increase, relative to the situation in 1995 , is particularly pronounced in India (plus 6 percentage points, or a 67 per cent increase relative to 1996), Japan (5 percentage points and a 60 per cent increase) and the PRC (4 percentage points and a 41 per cent increase). ${ }^{11}$

9 For example, Bernhardt and Milberg (2011) found considerable variations in economic and social upgrading across countries and industries using micro-data on four sectors: horticulture, apparel, tourism and mobile telephones.

10 However, this approach has two caveats. The first one is to blur the heterogeneity that exists between different firms belonging to the same industrial sector in the same country. By definition, outsourcing and GVC insertion involve a strategic decision taken by individual firms and not all enterprises may implement the same strategy. Second, it is probable that the employment impacts that we measure are overestimated. The firms that are active in international trade are usually large firms, which are more productive than smaller ones and employ fewer workers per unit of output. Because our estimates are based on sectoral averages mixing small and large firms that are oriented to serving the domestic market or active in international trade, the relationship between trade in value added and underlying employment is probably overstated. On efforts to overcome these problems, see Koopman, Wang and Wei (2012); Tang, Wang and Wang (2014); and Ma, Wang and Zhu (2015).

11 However, it is erroneous to understand these figures as net job creation. Some of the jobs created in one country to satisfy final demand in another country may displace the domestic labour in the latter. Competition from cheap labour forces abroad has often been identified as a cause of stagnant or even declining demand for low-skilled workers in the US. In this light, the frequently asked questions are: What would have happened if emerging countries had been less successful in their industrialisation? What would happen to manufacturing employment if US firms re-shored the tasks they had outsourced to developing countries? Such thought experiments are useful in their own right, but it is difficult to find evidence to determine answers because some of the tasks performed by human hands in developing countries could be substituted by the work of robots in developed countries. 


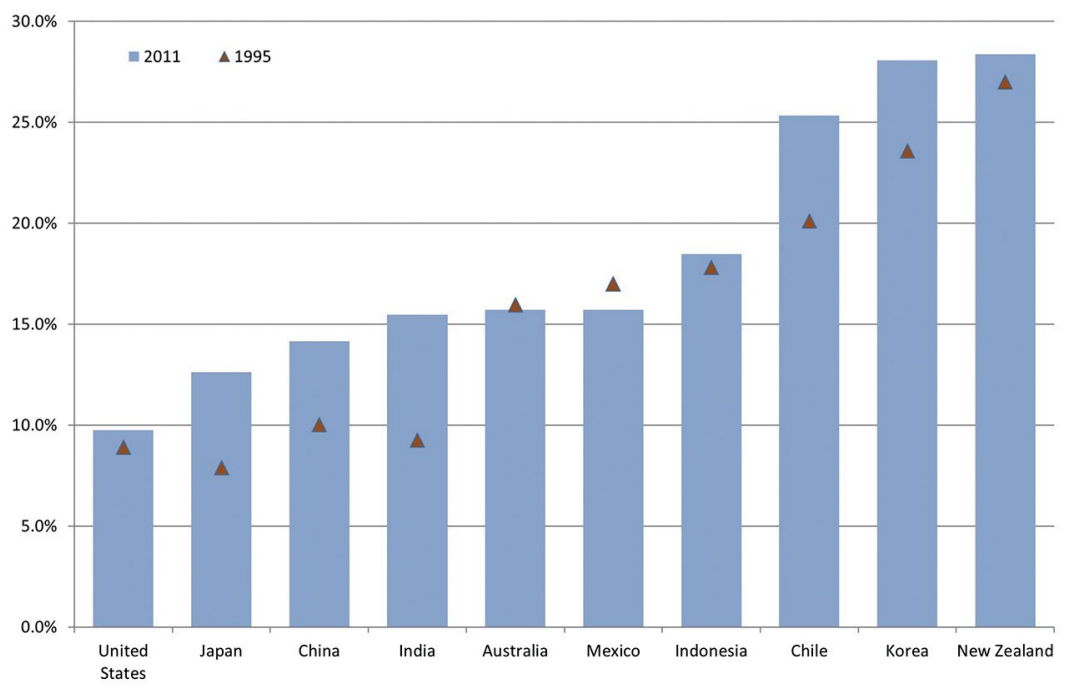

Figure 6.6: Share of domestic employment directly and indirectly created by exports, 1995-2011

Source: Based on OECD (2016).

The industrial origin of jobs created by exports varies from country to country (see Figure 6.7). Developed countries, shown on the left-hand side of Figure 6.7, specialise in services, particularly $R \& D$ or business services, in which they have so far maintained their comparative advantage. Conversely, countries rich in natural resources create more employment opportunities in their primary sectors. This is particularly the case in Indonesia, but also in the PRC and India. Australia, despite being a developed economy, has a strong primary-based export sector. It may seem surprising that Chile, the world's largest exporter of copper, does not reflect its gross export specialisation in the number of jobs related to its large mining sector. This apparent paradox reflects the fact that modern mining industries are highly capital-intensive and, thus, generate a relatively low amount of employment. By contrast, most of the jobs indirectly related to extracting operations are supporting activities, such as maintenance, energy supply and transportation, classified under the service sector rather than the mining sector per se. 


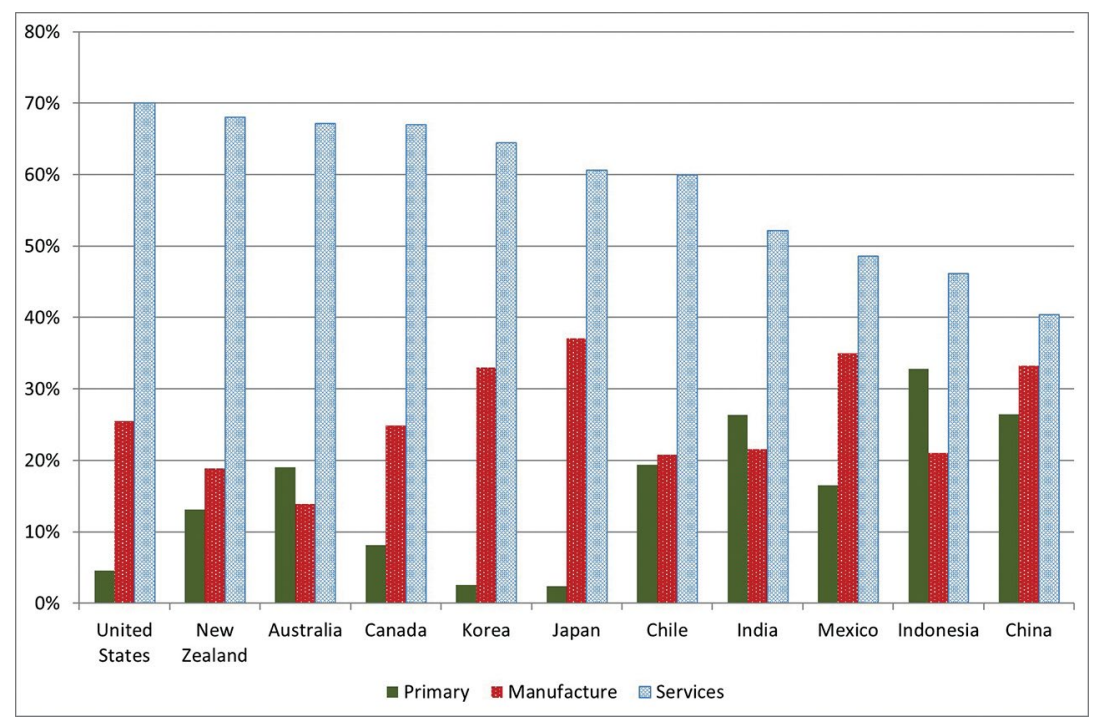

Figure 6.7: Sectoral share of employment directly and indirectly created by exports (2011)

Source: Based on OECD (2016).

When it comes to considering the performance of non-exporting sectors, some firms may indirectly participate in export efforts by providing intermediate products to lead exporting firms. This mode of GVC participation is particularly important for providers of services (which are traditionally considered as 'non-tradeable') or for small- and mediumsized firms that do not have the capacity to engage in global market operations. Compared with the previous import-substitution industrial policies that privileged the development of large-scale, full-set industries, the utilisation of more flexible networks of efficient, second-tier suppliers is one of the distinctive features of the new mode of industrialisation. ${ }^{12}$

In Figure 6.8, the shares of direct and indirect job creation by exports are relatively balanced across countries. Mexico and the PRC present contrasting pictures. Exports account for 10 per cent of direct employment

12 Indeed, the most distinctive feature of GVC-based industrial policies is simply the recognition that some inputs or tasks are better being imported or offshored than being sourced at home. The motto 'capture as much value added as you can' that underlines many GVC-related researches is a viable remedy for industrial failure and a waste of resources. GVC governance is not a zero-sum game like that of the mercantilist approach but a win-win strategy that opens up opportunities for many (although it should be recognised that there could be also losers from the process, whose situation needs to be addressed by public authorities). 
in Mexico, while in PRC this figure is only half that, at about 5 per cent. This seems counterintuitive in the case of the PRC, especially when recalling the example of electronic products assembly, involving a very low level of integration with the domestic economy. However, it should be noted that the PRC's exports are also concentrated within the heavy industries (e.g. steel and metal products) that purchase bulk inputs from the rest of the economy (energy, raw material, transportation services and so on), thereby forming strong domestic linkages all over the country. Conversely, Mexico, owing to its geographical proximity to the US, exports more services than does the PRC.

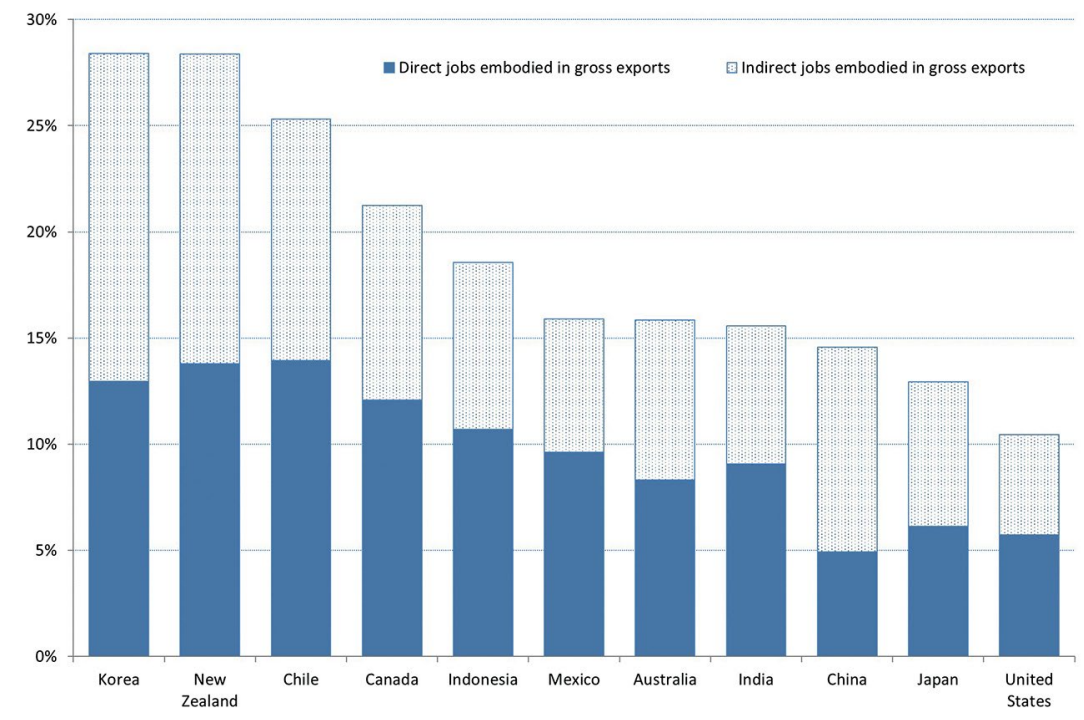

Figure 6.8: Direct vs indirect job creation by exports (2011)

Source: Based on OECD (2016).

Another important aspect of globalisation is the polarisation of income resulting from a switch in demand towards labour with higher qualifications. Despite a growing interest in this issue, it is not easy to test empirically whether offshoring activities create or destroy domestic jobs in different ways for different levels of qualification, particularly because most of the structural changes in labour markets are triggered by technological innovations or changes in consumer demand.

Figure 6.9 shows that the countries that have experienced a significant shift from low- and medium-skills towards higher qualifications are not mature economies, but mainly middle-income, developing economies. 
Indeed, the US experienced the smallest structural change in labour demand. Curiously, the PRC, after the US, has been quite stable in the distribution of export-related demand for jobs by skill levels. ${ }^{13}$

Irrespective of development status, the export-related demand for lowskilled jobs has fallen in all countries, whereas demand for higher-skilled ones is on the rise. The most salient change is the profile of mediumskilled jobs in countries competing for relative advantages on the export markets. Three countries (Korea, Canada and the US) registered a drop in the relative demand for medium-skilled workers, whereas other countries had positive demand (although sometimes only on a small scale, such as the case of Japan). Mexico is prominent among the countries promoting medium-skilled tasks that are related to exports. A possible explanation for this is that Mexico, facing tough competition with the PRC for its traditional maquiladora (low-cost assembly) exports to the US, may have striven to achieve a significant industrial upgrading, shifting from producing low value-added products using cheap labour force to higher value-added products that employ more medium-skilled workers.

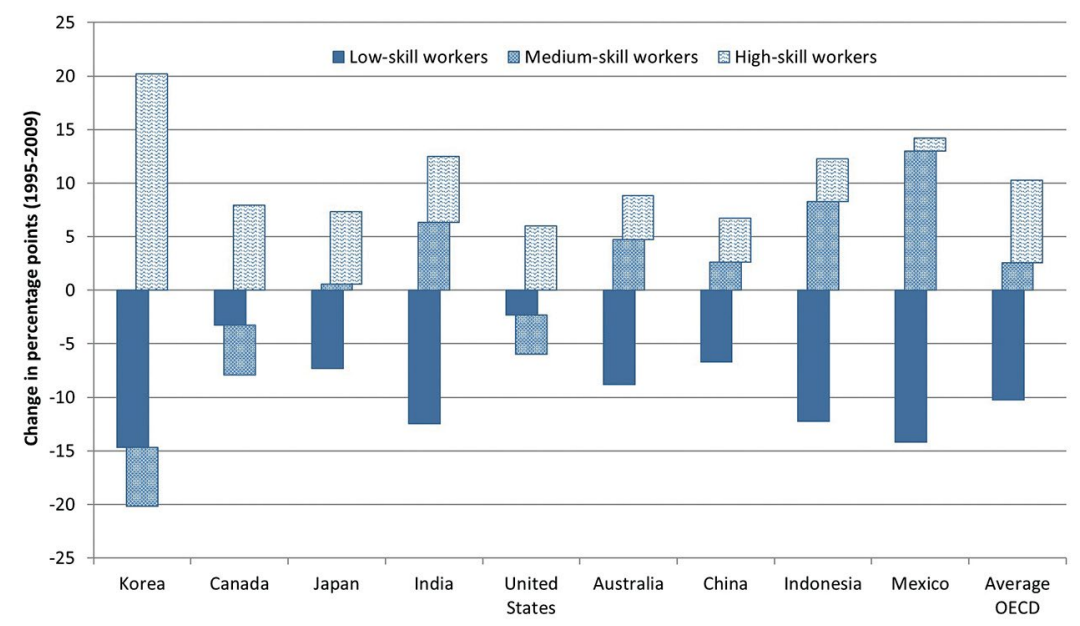

Figure 6.9: Structural change in export-related employment by skills (1995-2009)

Source: Based on OECD (2016).

13 Measuring the differential through standard deviation, the US has the lowest dispersion (5.2), followed by China (5.9), which was much lower than the OECD average of 9.2 or Korea's high mark of 18.1 . 


\section{Conclusions}

The concept of GVCs has reshaped our understanding of comparative advantage and international economics. As a result of progress in statistics as well as methodological advancement in input-output analyses and graph theories, we are now in a position to map and visualise international production networks by tracing supply-use relations of goods and services between industries and across borders.

This chapter has provided some evidence about the nature of GVCs in the Asia-Pacific region, with particular attention to cross-national transfers of value added and employment opportunities. We have provided a numeric description of the structure of the production networks, using the multicountry input-output table as a principal analytical tool.

Following a brief overview of prior empirical works, we examined the evolution of regional production networks in the Asia-US region. From 1985 to 2005, the inter-industrial network moved from a simple hub and spokes cluster, centred on Japan, to a much more complex structure following the emergence of the PRC that involved various countries as secondary pivots. We also identified the relative position of countries within the regional production networks, which revealed the role and specialisation of each economy in the region's vertical production system.

Comprehensive utilisation of the OECD-WTO TiVA database elucidated some key features about the configuration of GVCs. The cross-national transfer of value added was highly regionalised at the outset of economic globalisation, with North America, Europe and Asia operating as three value chain clusters. However, this gradually changed, as the US and the PRC continued to expand their production networks all over the world.

In this process, reorganisation of production systems based on crosscountry comparative advantages took place, which had a significant effect on the relative demand for labour by skill levels. The demand for low-skilled jobs went down, whereas the demand for high-skilled tasks increased, and this was the case across both developed and developing Asian-Pacific economies. However, depending on the country's status of economic development, the demand for medium-skilled workers involved considerable variation. 
The increasing complexity of production networks that we observe today requires a very careful treatment of the statistical assets that are available because analytical results become more and more sensitive to the ways that the relevant information is handled. While MCIOTs assist greatly in understanding production networks, the model remains at an early stage of development and considerable effort must be invested in upgrading the database to capture the full implications of economic globalisation for our societies.

\section{References}

Bernhardt, T. \& Milberg, W. (2011). Economic and social upgrading in global value chains: Analysis of horticulture, apparel, tourism and mobile telephones. Working Paper No. 6, Capturing the Gains Project. Manchester, England: University of Manchester.

Borgatti, S. (2005). Centrality and network flow. Social Networks, 27(1), 55-71. doi.org/10.1016/j.socnet.2004.11.008

Chen, X., Cheng, L., Fung, K. C. \& Lau, L. (2009). The estimation of domestic value-added and employment induced by exports: An application to Chinese exports to the United States. In Y. W. Cheung \& K. Y. Wong (Eds.), China and Asia: Economic and financial interactions. London, England: Routledge.

Daudin, G., Monperrus-Veroni, P., Rifflart, C. \& Schweisguth, D. (2006/ French version, 2009/English version). Who produces for whom in the world economy? OFCE Document de travail No. 2009-18. Paris: Observatoire Francais des Conjonctures Economiques.

Dedrick, J., Kraemer, K. \& Linden, G. (2008). Who profits from innovation in global value chains? A study of the iPod and notebook PCs. Industry Studies 2008. Irvine, CA: Personal Computing Industry Center.

Dietzenbacher, E., Romero, I. \& Bosma, N. S. (2005). Using average propagation lengths to identify production chains in the Andalusian Economy. Estudios de Economia Aplicada, 23, 405-22. 
Escaith, H. (2014). Mapping global value chains and measuring trade in tasks. In B. Ferrarini \& D. Hummels (Eds.), Asia and global production networks: Implications for trade, incomes and economic vulnerability. Cheltenham, UK: Asian Development Bank and Edwards Elgar Publishing. doi.org/10.4337/9781783472093.00015

Escaith, H. \& Inomata, S. (2013). Geometry of global value chains in East Asia: The role of industrial networks and trade policies. In D. Elms \& P. Low (Eds.), Global value chains in a changing world. Geneva, Switzerland: Fung Global Institute, Nanyang Technological University and World Trade Organization.

Farolle, T. (2016, August). Do global value chains create jobs? IZA World of Labor, 291. doi.org/10.15185/izawol.291

Gereffi, G., Humphrey, J. \& Sturgeon, T. (2005). The governance of global value chains. Review of International Political Economy, 12(1), 78-104. doi.org/10.1080/09692290500049805

Hummels, D., Ishii, J. \& Yi, K-M. (2001). The nature and growth of vertical specialization in world trade. Journal of International Economics, 54(1), 75-96. doi.org/10.1016/S0022-1996(00)00093-3

Inomata, S. (2008). Average propagation lengths: A new concept of the 'distance' between industries, with an application to the Asia-Pacific Region. Sangyo-Renkan, 16(1) (in Japanese).

Inomata, S. (2017). Analytical frameworks for global value chains: An overview. In World Bank, Global Value Chain Development Report 2017 (Chapter 1). Washington, DC: The World Bank Group.

Johnson, R. C. \& Noguera, G. (2012). Accounting for intermediate production sharing and trade in value added. Journal of International Economics, 86, 224-36. doi.org/10.1016/j.jinteco.2011.10.003

Koopman, R. B., Wang, Z. \& Wei, S. J. (2012). Estimating domestic content in exports when processing trade is pervasive. Journal of Development Economics, 99(1), 178-89. doi.org/10.1016/j. jdeveco.2011.12.004

Ma, H., Wang, Z. \& Zhu, K. (2015). Domestic content in China’s exports and its distribution by firm ownership. Journal of Comparative Economics, 43, 3-18. 
Miroudot, S. and Nordstrom, H. (2015). Made in the world? Robert Schuman Centre for Advanced Studies Research Paper No. RSCAS 2015/60. Florence, Italy: European University Institute.

Organisation for Economic Co-operation and Development (OECD). (2016, June). Global value chains and trade in value added: An initial assessment of the impact on jobs and productivity. OECD Paper TAD/ TC/WP (2015)10/FINAL. Paris, France: OECD.

Sturgeon, T. J., Nielsen, P. B., Linden, G., Gereffi, G. \& Brown, C. (2013). Direct measurement of global value chains: Collecting product- and firm-level statistics on value added and business function outsourcing and offshoring. In A. Mattoo, Z. Wang \& S-J. Wei (Eds.), Trade in value added: Developing new measures of cross-border trade (pp. 289-320). Washington, DC: The World Bank.

Tang, H., Wang, F. \& Wang, Z. (2014). The domestic segment of global supply chains in China under state capitalism. Working Paper No. 186. Dallas, Texas: Federal Reserve Bank of Dallas Globalization and Monetary Policy Institute.

\section{Appendix A: Technical notes}

\section{Technical Note 6.1: Calculation of APL}

The conventional input-output approach to supply chains analyses generally focuses on measuring interconnectedness, or the strength of linkages among industries, based on the traditional demand-pull or costpush impact models. The increasing complexity of production systems requires measurement, not just of the strength, but also of the 'length' of linkages for mapping production networks.

The length dimension of production linkages was first addressed by the input-output model of APL developed by Dietzenbacher, Romero and Bosma (2005). The APL represents the average number of production stages lining up in every branch of production networks. Therefore, it effectively measures an industry's level of fragmentation.

Suppose that there is an n-sector economy with a production structure defined by the input coefficient matrix $\boldsymbol{A}$, as shown in Figure A6.1a. Input coefficients $a_{i j}$ are calculated from an input-output table by dividing 
input values of goods and services used in each industry by the industry's corresponding total output, that is, $a_{i j}=z_{i j} / X_{j}$, where $z_{i j}$ is the value of $\operatorname{good} /$ service $i$ purchased for the production of industry $j$, and $X_{j}$ is the total output of industry $j$. Then, the coefficients represent the direct requirement of inputs for producing just one unit of output of industry $j$.

$$
A=\left[\begin{array}{ccccc}
a_{11} & a_{12} & a_{13} & \ldots & a_{1 n} \\
a_{21} & a_{22} & a_{23} & \ldots & a_{2 n} \\
a_{31} & a_{32} & a_{33} & \ldots & a_{3 n} \\
\vdots & \vdots & \vdots & \ddots & \vdots \\
a_{n 1} & a_{n 2} & a_{n 3} & \ldots & a_{n n}
\end{array}\right]
$$

Figure A6.1a: An input coefficient matrix

One-step path

Ind $3 \stackrel{a_{13}}{\longrightarrow}$ Ind 1

Two-step path

$$
\begin{array}{ccccc}
\text { Ind3 } 3 & \stackrel{a_{23}}{\longrightarrow} & \text { Ind } 2 & \stackrel{a_{12}}{\longrightarrow} & \text { Ind } 1 \\
\text { Ind3 } & \stackrel{a_{33}}{\longrightarrow} & \text { Ind } 3 & \stackrel{a_{13}}{\longrightarrow} & \text { Ind } 1 \\
: & & : & & : \\
& & & \text { and } & \text { so on }
\end{array}
$$

Figure A6.1b: Impact delivery paths

The vertical sequence of production propagation can be understood using Figure A6.1b, described as follows. Let us consider the effect of extra demand for 100 units in sector 3 upon the output of sector 1 . The simplest form of all is given by the direct linkage [ $3 \rightarrow 1]$, which is calculated as a product of multiplying 100 units by input coefficient $a_{13}$. This is because $a_{13}$, by definition of an input coefficient, represents the immediate amount of good 1 required for producing just one unit of good 3. Alternatively, there is a two-step path going through another industry, say, $[3 \rightarrow 2 \rightarrow 1]$. This is derived by two-stage multiplication, that is, 100 units by $a_{23}$, and then by $a_{12}$. Alternatively, there could be a two-step path going through the same sector, such as $[3 \rightarrow 3 \rightarrow 1]$ or $[3 \rightarrow 1 \rightarrow 1]$, which would be derived respectively as [100 $\left.\mathrm{x} a_{33} \times a_{13}\right]$ or $\left[100 \times a_{13} \times a_{11}\right]$ (see Figure A6.1b).

The exercise reveals that the impact of any two-step path, whatever the sequence of sectors, can be given by reinjecting a set of direct impacts back into the input coefficient matrix, that is, $\boldsymbol{A}^{1} \times \boldsymbol{A}=\boldsymbol{A}^{2}$. Similarly, the impact of three-step paths is given by $\boldsymbol{A}^{2}$ х $\boldsymbol{A}=\boldsymbol{A}^{3}$, that of four-step paths by $\boldsymbol{A}^{3} \mathrm{x}$ 
$\boldsymbol{A}=\boldsymbol{A}^{4}$ and so on, which is evident from $\left[\boldsymbol{A}^{2}\right]_{i j}=\sum_{k} a_{i k} a_{k j}\left[\boldsymbol{A}^{3}\right]_{i j}=\sum_{k} \sum_{h} a_{i k} a_{k h} a_{h j}$, and so on. The amount of impacts shown in each layer of $\boldsymbol{A}^{\mathrm{k}_{\mathrm{s}}}(k=1,2$, $3, \ldots$,$) are a result of the initial demand injection passing through all k$-step paths. They capture the effect of every direct and indirect linkage that undergoes exactly the $k$-steps of the production process with $k$ segments of production stages.

Meanwhile, it is mathematically known that a Leontief inverse matrix $\boldsymbol{L}$, which shows the total amount of goods and services required for the production of one unit of output, can be expanded as an arithmetic series, that is, $\boldsymbol{L}=(\boldsymbol{I}-\boldsymbol{A})^{-1}=\boldsymbol{I}+\boldsymbol{A}+\boldsymbol{A}^{2}+\boldsymbol{A}^{3}+\boldsymbol{A}^{4}+\ldots$, where $\boldsymbol{I}$ is an identity matrix (with one in diagonal elements and zero elsewhere). From the above, it is immediately clear that the equation represents the decomposition of the total impact on output into its constituent impact layers according to the number of production stages involved. $\boldsymbol{I}$ is an initial demand injection, and the following $\boldsymbol{A}^{\mathrm{k}} \mathrm{s}$ are regarded as progressive impacts of the initial demand when production chains are sliced at the $k^{\text {th }}$ stage of the production process.

With this preliminary understanding, APL is defined as:

$$
\begin{aligned}
& v_{i j}=1 * a_{i j} /\left(l_{i j}-\delta_{i j}\right)+2 *\left[A^{2}\right]_{i j} /\left(l_{i j}-\delta_{i j}\right)+3 *\left[A^{3}\right]_{i j} /\left(l_{i j}-\delta_{i j}\right)+\cdots \\
& =\sum_{k-1}^{\infty} k\left[\left[A^{k}\right]_{j j} / \sum_{k-1}^{\infty}\left[A^{k}\right]_{j j}\right]
\end{aligned}
$$

where $\boldsymbol{A}$ is an input coefficient matrix, $a_{i j}$ is its element, $l_{i j}$ is a Leontief inverse coefficient, $\delta_{i j}$ is a Kronecker delta, which is $\delta_{i j}=1$ if $i=j$ and $\delta_{i j}$ $=0$ otherwise, and $k$ is the number of production stages along the path. We also define that $v_{i j}=0$ when $\left(l_{i j}-\delta_{i j}\right)=0$.

The first term on the right-hand side of the upper equation shows that the impact delivered through one-step paths $(k=1)$, that is, the direct impact, amounts to an $a_{i j} /\left(l_{i j}-\delta_{i j}\right)$ share of the total impact given by the Leontief inverse coefficient (less unity for diagonal elements because of $\delta_{i j}$ ).

Similarly, two-step paths $(k=2)$ contribute an $\left[\boldsymbol{A}^{2}\right]_{i j} /\left(l_{i j}-\delta_{i j}\right)$ share, and three-step paths $(k=3)$ an $\left[\boldsymbol{A}^{3}\right]_{i j} /\left(l_{i j}-\delta_{i j}\right)$ share of the total impact. This is evident from $\boldsymbol{L}=\boldsymbol{I}+\boldsymbol{A}+\boldsymbol{A}^{2}+\boldsymbol{A}^{3}+\ldots$, which is rearranged as $\boldsymbol{L}-\boldsymbol{I}=\boldsymbol{A}$ $+A^{2}+A^{3}+\ldots$, and hence $(L-I)_{i j}=A_{i j}+\left[A^{2}\right]_{i j}+\left[A^{3}\right]_{i j}+\ldots$ 
That is, APL is formulated as a weighted average of the number of the production stages that an impact from industry $j$ goes through until it ultimately reaches industry $i$, using the share of impact at each stage as a weight. It represents the average number of production stages lining up in every branch of all the production chains or, in short, an industry's level of fragmentation.

\section{Technical Note 6.2: Calculation of TiVA}

A value-added export from country $r$ to country $s$ is calculated as:

$$
\text { TiVArs }=\boldsymbol{v}^{r} \cdot \boldsymbol{L} \cdot \boldsymbol{f}^{*_{s}} \quad(\mathrm{r} \neq \mathrm{s})
$$

where $\boldsymbol{v}^{r}$ is a value-added rate vector (row) of country $r, \boldsymbol{L}$ is an international Leontief inverse matrix and $\boldsymbol{f}^{*}$ is a final demand vector (column) of country s. $\boldsymbol{L} \boldsymbol{f}^{* s}$ on the right-hand side of the equation gives the amount of each country's sectoral output induced, directly and indirectly, by the final demand of country $s$ (both for domestic and imported products). As a value-added rate represents the amount of value added generated by one unit of production, multiplying country $r$ 's rate by the amount of the induced output, as given above, produces the value added of country $r$ generated by the final demand of country $s$, which is understood as the value-added export from country $r$ to country $s$.

In the two-country, two-product setup, the value-added export from country $r$ to country $s$ will be:

$T i V A^{r s}=\left[\begin{array}{llll}v_{1}^{r} & v_{2}^{r} & 0 & 0\end{array}\right]\left[\begin{array}{llll}l_{11}^{r r} & l_{12}^{r r} & l_{11}^{r s} & l_{12}^{r s} \\ l_{21}^{r r} & l_{22}^{r r} & l_{21}^{r s} & l_{22}^{r s} \\ l_{11}^{s r} & l_{12}^{s r} & l_{11}^{s s} & l_{12}^{s s} \\ l_{21}^{s r} & l_{22}^{s r} & l_{21}^{s s} & l_{22}^{s s}\end{array}\right]\left[\begin{array}{l}f_{1}^{r s} \\ f_{2}^{r s} \\ f_{1}^{s s} \\ f_{2}^{s s}\end{array}\right]$

and the value-added export from country s to country $r$ is given as:

$T i V A^{s r}=\left[\begin{array}{llll}0 & 0 & v_{1}^{s} & v_{2}^{s}\end{array}\right]\left[\begin{array}{llll}l_{11}^{r r} & l_{12}^{r r} & l_{11}^{r s} & l_{12}^{r s} \\ l_{21}^{r r} & l_{22}^{r r} & l_{21}^{r s} & l_{22}^{r s} \\ l_{11}^{s r} & l_{12}^{s r} & l_{11}^{s s} & l_{12}^{s s} \\ l_{21}^{s r} & l_{22}^{s r} & l_{21}^{s s} & l_{22}^{s s}\end{array}\right]\left[\begin{array}{l}f_{1}^{r r} \\ f_{2}^{r r} \\ f_{1}^{s r} \\ f_{2}^{s r}\end{array}\right]$ 


\section{Technical Note 6.3: Calculation of employment content of trade}

The method introduced above for the measurement of TiVA can be applied to the calculation of the employment content of trade by simply swapping the value-added rate vector $\boldsymbol{v}^{r}$ for the employment rate vector $\boldsymbol{w}^{r}$, which represents the number of workers required to produce one unit of output. That is:

TiEmprs $=\boldsymbol{w}^{r} \cdot \boldsymbol{L} \cdot \boldsymbol{f}^{* s} \quad(\mathrm{r} \neq \mathrm{s})$ 
This text is taken from Asian Economic Integration in an Era of Global Uncertainty, edited by Shiro Armstrong and Tom Westland, published 2018 by ANU Press, The Australian National University, Canberra, Australia. 